\title{
NILAI-NILAI PENDIDIKAN AGAMA HINDU DALAM LONTAR KRAMA PURA
}

\author{
ANAK AGUNG GEDE DIRA
}

\author{
PRODI ILMU FILSAFAT AGAMA HINDU \\ FAKULTAS ILMU AGAMA DAN KEBUDAYAAN \\ Email: agungdira@ unhi.ac.id
}

\begin{abstract}
ABSTRAK
Artikel ini mencoba membahas tentang nilai pendidikan agama Hindu dalam Lontar Krama pura. Ada pun beberapa hal yang akan dibahas yakni: (a) Nilai pendidikan tattwa, (b). nilai-nilai pendidikan susila yang lebih menekankan tentang peraturan yang wajib ditaati jika akan masuk ke areal pura (c) nilai-nilai pendidikan upacara yang lebih menekankan pada upacara keagamaan yang wajib dilakukan oleh umat apabila umat melanggar tata tertib masuk pura, berupa upacarabhuta yadnya, yaitu melaksanakan upacara pecaruan besar - kecilnya sesuai kesalahan yang dilakukan oleh umat.
\end{abstract}

\section{Kata Kunci: tattwa, susila, upacara}

\section{PENDAHULUAN}

Pulau Bali adalah salah satu bagian kecil dari kepulauan Indonesia yang memilki keunikan-keunikan yang tidak dimiliki oleh pulau lain di Indonesia, salah satu keunikan yang dimaksud adalah satu-satunya pulau yang mayoritas masih memeluk agama Hindu, yang mana ulau lain seperti pulau Jawa, pulau Sumatra dan Kalimanmtan yang pada masa lalu penduduknya mayoritas memeluk agama Hindu kini menjadi pulau yang penduduknya minoritas memeluk agama Hindu. Pulau jawa pada masa periode abad ke V sampai abad ke $X V$, selama sepuluh abad merupakan pusat perkembangan agama Hindu di Asia Tenggara.
Seiring dengan bergulirnya sang waktu, sejak runtuhnya kerajaan Majapahit sebagai kerajaan terbesar di Nusantara, pengaruh Hindupun mulai pudar, dan akhirnya menjadi agama yang minoritas. Kecuali pulau Bali, satu-satunya pulau yang masih bertahan penduduknya memeluk agama Hindu secara Mayoritas. Tetap bertahannya agama Hindu di Bali secara mayoritas menurut teori batas akal memang atas kehendak Tuhan Yang Maha Esa, namun secara ilmiah masih ditemukan sebab-sebabnya. Sebab bertahannya agama Hindu di Bali secara logis dan populer karena di Bali diberlakukannya sistem Desa Pakraman. Desa Pakraman adalah suatu Desa yang yang bersifat magis religius Hinduistis. Desa pakraman diikat oleh tanggung jawab 
keagamaan yang sangat besar dan kuat, dimana setiap desa pakraman diikat oleh tanggung jawab keagamaan berupa Kahyangan Tiga. Yang bertanggung jawab atas Kahyangan Tiga adalah Krama Desa Pakraman yang ada di Desa tersebut. Sehingga Kahyangan Tiga merupakan ikatan yang paling kuat untuk mempertahankan Agama Hindu di masing-masing Desa Pakraman.

Desa Pakraman memilki aturanaturan Lokal yang sangat ketat yang disebut awig-awig. Awig-awig inilah yang mengikat warga desa dalam ikatan sosial kemasyarakatan dan ikatan sosial keagamaan. Ikatan sosial keagamaan sangat ampuh mengikat umat Hindu di Bali adalah sistem tempat sucikeluarga seperti pelinggih Ibu, pelinggih panti, pelinggih Dadia, dan pedarman. Bila sistem ini dapat diterapkan dengan baik, dan benar, maka akan dapat menjaga sistem kekeluargaan bagi sesama warga dan menjaga kerukunan intern umat beragama. Sehingga menjadi benteng keberagamaan yang sangat kuat untuk mempertahankan agama Hindu.

Agama Hindu juga bersifat sangat fleksibel dalam penerapannya dapat disesuaikan dengan zaman. Pada pelaksanaanya agama Hindu menggunakan kendaraan Budaya dan diperindah oleh seni, sehingga pada penampilan luarnya agama Hindu menjadi Indah unik dan menarik. Agama Hindu tergolong agama besar karena telah memenuhi empat syarat pokok yaitu: mempunyai orang suci, mempunyai kitab suci, mempunyai hari suci, dan mempunyai tempat suci.

Keempat persyaratan itu dipenuhi oleh agama Hindu, maka dari itu agama Hindu tergolong agama besar, bahkan terbesar, terlengkap dan tertua. Saking tuanya ajaran agama Hindu dan tetap dapat bertahan sampai saat ini, menjadikan ajaran agama Hindu abadi, maka dari itu agama Hindu diberi julukan Sanatana Dharma, yang artinya kebenaran yang kekal abadi.

Orang suci agama Hindu yang dapat menerima wahyu atau pawisik dari Tuhan disebut Maha Resi. Dalam Weda disebutkan "Mantra drestah iti resih" yang artinya Resi adalah ia yang dapat menerima mantra. Orang suci yang membangun agama Hindu bukanlah satu orang, layaknya agama abrahamik seperti agama Kristen dan Islam. Tetapi agama Hindu dibangun oleh banyak orang-orang suci yang telah mencapai kesempurnaan, maka dari itu orang suci agama Hindu lebih tepat disebut Maha Resi, bukan Nabi.

Persyaratan yang kedua yaitu kitab suci, kitab suci agama Hindu disebut Weda, Weda yang merupakan sabda suci dari Tuhan yang dapat didengar secara langsung oleh para Maha Resi, oleh karena itu disebut Weda Sruti. Sedangkan penjelasan dari Weda Sruti disebut Weda Smerti. Sedangkan ribuan buku yang menguraikan tentang agama Hindu disebut Pustaka Suci. Persyaratan yang ketiga ialah hari suci, hari suci agama Hindu Nusantara dapat dibagi dua, hari raya yang berdasarkan $W u k u$ dan Wewaran datangnya setiap 210 hari sekali. Hari raya ini merupakan produk asli kearifan lokal umat Hindu Nusantara. Hari suci yang dimaksud antara lain : hari raya Galungan, hari raya Kuningan, hari raya Saraswati, dan lain sebagainya. Hari suci berikutnya adalah berdasarkan Sasih Naksatra, datangnya setiap tahun sekali, hari suci yang dimaksud antara lain, hanya Siwaratri dan hari raya Nyepi. 
Persyaratan yang keempat adalah tempat suci, nama tempat suci agama Hindu bukanlah satu, melainkan banyak. Pada masa kejayaan Hindu di Nusantara tempat suci agama Hindu disebut Candi. Pada masa sekarang tempat suci agama Hindu Nusantara disebut Pura. Tempat suci agama Hindu yang disebut Pura telah tersebar dan dibangun oleh umat Hindu Nusantara dimana saja mereka berada. Pura pada mulanya mulai dibangun di Bali sejak kedatangan $\mathrm{Mpu}$ Kuturan tepatnya sekitar abad X masa Raja Udayana Warmadewa. Pura merupakan tempat suci bagi umat Hindu yang amat disucikan keberadaannya dan dibangun secara khusus pula, dari mulai menentukan lokasi Pura, hari baik (dewasa) mulai membangun Pura, proses kronologis membangun Pura, mulai ngeruak (membuka lahan), nyukat (mengukur lokasi Pura), mendem dasar (peletakan batu pertama), upacara memukuh, mendem pedagingan, mlaspas dan ngenteg linggih. Proses upacara yang sangat sakral itulah Pura bagi umat Hindu merupakan tempat suci yang sangat disakralkan, sangat disucikan dan sangat diistimewakan oleh umat Hindu.

Setelah Pura itu di plaspas, maka Pura tersebut statusnya telah suci dan dapat difungsikan sebagai tempat persembahyangan bagi umat Hindu, karena itu kesucian, kebersihan, keasriannya perlu dijaga oleh umatnya sendiri. Guna tetap menjaga kesucian Pura, biasanya desa pakraman sebagai pengemong dan pengempon Pura mempunyai aturan-aturan baik yang tertulis maupun yang tidak tertulis, agar Pura tetap terjaga kesuciannya. Aturanaturan yang tertulis di desa pakraman disebut awig-awig. Sedangkan peraturan yang tidak tertulis disebut dresta atau kebiasaan-kebiasaan. Peraturan-peraturan khusus yang menyangkut Pura disamping diatur dalam awig-awig desa pakraman, juga diatur dalam sastra agama Hindu yang disebut lontar. Terdapat banyak lontar yang ditemukan di Bali, sebagai bukti kreatifitas keagamaan tempo dulu sangat tinggi. Diantara lontar yang ditemukan dapat dibagi dalam beberapa kelompok sesuai dengan sifat isinya.

Lontar-lontar yang cukup banyak jumlah jenisnya dapat dibagi menjadi (1) kelompok puja, (2) kelompok tattwa, (3) kelompok sesana, (4) kelompok yadnya (Sura, 1991: 31). Yang termasuk lontar puja adalah Weda Parikrama, Surya Sewana, Kusuma Dewa, Kajang Pitra Puja. Yang tergolong lontar sesana antara lain Siwa Sesana, Agastya Parwa, Silakrama, Wdati Sesana. Diantara lontar sesana ada lontar yang sangat penting untuk mendapat perhatian yaitu sebuah lontar yang mengatur tentang tata cara menjaga kesucian pura. Terkait dengan permasalahan untuk tetap menjaga kesucian Pura, ada sebuah sastra agama Hindu yang membahas tentang tatacara menjadi kesucian Pura dan sanksi-sanksinya. Lontar itu berjudul Lontar Krama Pura. Menurut hemat peneliti isi lontar ini sangat penting diketahui oleh umat Hindu yang pasti mengemong sebuah Pura, agar kesucian Pura tetap terjaga sepanjang masa. Berdasarkan latar belakang itulah peneliti memilih judul Nilai-nilai Pendidikan Agama Hindu dalam Lontar Krama Pura.

\section{PEMBAHASAN}

\subsection{Nilai Pendidikan Tattwa}

Tattwa berasal dari bahasa sansekerta, secara leksikal berasal dari kata tat 
artinya, hakikat, kebenaran, kenyataan, twa artinya sifat. Tattwa artinya bersifat kebenaran, atau mengandung nilai kebenaran (menurut pandangan agama Hindu). Dalam lontar krarma pura nilainilai pendidikan tattwa yang terkandung didalamnya adalah tentang keyakinan kepada Tuhan Yang Maha Suci yang tidak terbatas Tuhan itu gaib, beliau tak terbakar oleh api (adahya). Dalam lontar kramapura dinyatakan secara inplisit bila kesurupan dirasuki oleh Tuhan (dewa) maka kebenarannya harus diuji kebenarannya apakah benar dirasuki energy Tuhan, sebagaimana dinyatakan dalam lontar Kramapura sebagai berikut.

Malih yan hana jadma tedun katinganan mangaku-ngaku dewa pangakune wenang ya pintonin antuk bau kaun bulu, sapangkoning tangan kalih akinangan Suenya nanging maduluran banten, ring ajeng pura punika, yan tan tumamah genineriya, tuku dewa malingga riya, yening tumamah gemine tiga tan tuku dewa malingga riya, ika ta wenang tiniban danda mwang panyapuh kahyangan ika ngaran (Lontar Kramapura : 2)

Terjemahannya

Lagi bila ada orang yang kesurupan mengaku-ngaku dewa yang turun, hendaknya diuji dengan api botok kelapa, celupkan kedua tangannya, lamanya sama dengan orag makan sirih, namun disertai sesajen di depan pura itu, bila ia tidak terbakar oleh api, memang benar dewa yang bersemayam pada dirinya, bila ia terbakar oleh api, tidak benar dengan yang bersemayam pada dirinya, itu patut dikenakan denda dan menyucian Kahyangan (Tim Penterjemah 2008 : 3)
Secara inplisit pernyataan dalam lontar Krama pura di atas mengandung ajaran tatwa tentang hakikat Tuhan yang tak terbakar oleh api, sehingga apabila orang kerasukan dewa (prabawa Tuhan) Orang yang kesurupan pun akan tak terbakarkan oleh api, karena ia dilindungi oleh energi Tuhan. Demikian pula dinyatakan dalam kitab Bhagawadgita sebagai berikut.

Hainam chindanti sastr $\bar{a}_{n i}$
Nai nam dahati pawakah
Nacai, nam kcedayanti $\bar{a}_{\text {po }} \overline{\bar{a}}_{\text {rutah }}$
Na sesayatu magatr.23)
(Bhagawadgita II.

Terjemahan

Senjata tidak dapat melukainya dan api tidak dapat membakarnya angin tidak dapat mengeringkanya dan air tidak dapat membasahinya (Pudja, 1984 : 42)

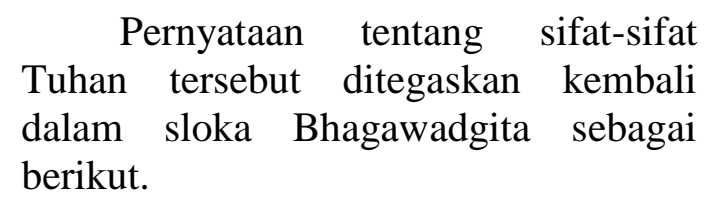

Acchedyo'yam adahyo" yam

Akledyo, sosya ewa ca

Nityah sarwagatah sthanur

Acalo 'yam sanatanah

(Bhagawadgita, II, 24)

Terjemahan

Sesungguhnya ia tidak dapat dilukai, dibakar

dan juga tidak dapat dikeringkan dan dibasahi

ia kekal tiada berubah, tidak

bergerak, dia abadi adanya 
Salah satu kemaha kuasaan Tuhan adalah tak terbakar oleh api (adahya) menurut kitab Bhagawadgita, dalam lontar Krama pura disebutkan apabila orang kerauhan atau disusupi oleh kemaha kuasaan Tuhan salah satu tandanya adalah apabila tubuhnya dibakar, orang yang kesurupan akan tak terbakar oleh api.

Lontar krama pura secara inplisit mengajarkan pemujaan terhadap Tuhan yang amat gaib yang tak dapat dipikirkan dan tak dapat terjangkau oleh pikiran dapat dipuja dengan media pralingga, berupa arca atau puspalingga sebagai simbol stana Ida Sanghyang Widhi dan Ista Dewatanya. Pemujaan Tuhan dengan menggunakan media pralingga disebut Murti puja . Pemujaan Tuhan dengan Murti puja sangat cocok bagi umat kebanyakan atau umat yang masih, tergolong awam. Logika pemujaan Tuhan dengan Murti puja amat tepat karena : Tuhan yang tidak terbatas tidak dibayangkan dengan pikiran yang terbatas, oleh karena itu manusia perlu menggunakan media sebagai batasannya guna mempermudah mewujudkan rasa bukti. Media batasan itulah dengan dibantu oleh pralingga pengadeg dewa. Pemujaan yang demikian disebut Murti dewa dalam agama Hindu. Sehubungan dengan hal tersebut dalam lontar Krama pura secara inplisit mengajarkan pemujaan Tuhan dengan cara Murti puja, selengkapnya sebagai berikut.

Melih yang wenten jadma menedunang pengadeganing dewa arca, maka daksina saluire pula pali magenah ring gedong, yan tan pakem Ipemangku, mekadi pamaksan muahne tan mula jurunya, yamnya saking angen-angen dewek teka wnang wong ika dosanen, ngaturang panyepuhan, acaru manca kelud, mwang ngaturang prayascita luih, apan salahnya lancang karna angungkuli srenggi ngaran.

\section{(Lontar Kramapura.3)}

Terjemahannya

Lagi bila ada orang yang menurunkan arca perwujudan dewa seperti daksina, segala sesuatu yang berada digedongnya bila tanpa perintah I pemangku, terutama pamaksan serta yang memang bukan petugasnya, hanya karena keinginan sendiri, orang yang demikian patut kena sanksi, melaksanakan upacara penyucian, dengan caru manca kelud dan menghaturkan prayascita utama, karena salahnya terlalu lancang (bagaikan) telinga melampoi tanduk namanya.

(Tim Penterjemah, $2008: 3$ )

Apabila dianalisis ucapan lontar Krama pura diatas pemujaan Tuhan dengan media pralingga menjadi penting karena pralingga amat disucikan dan disakralkan oleh umat pengempon pura karenanya tidak dibenarkan sembarangan orang untuk memindahkan dan menukarnya, sebab pralingga tersebut sudah menjadi simbol lingga stana ista Dewata. Jika alat-alat upakara sudah terbentuk sedemikian rupa sesuai dengan petunjuk sastra, maka dapat digunakan sebagai simbol pralingga atau_lingga stana Tuhan dalam berbagai manifestasinya. Dalam lontar yadnya prakerti disebutkan tentang arti dan makna banten sebagai berikut, sehananing bebanten pinaka raganta tan, pinaka warna rupaning Ida Bhatara, pinaka anda Bhuwana artinya : semua bebanten adalah lambang dirimu sendiri, lambang kemaha kuasaan 
Tuhan dan lambang alam semesta (Wiana, 2004 : 11). Banten sebagai lambang kemahakuasaan Tuhan antara lain banten canang yang dilengkapi dengan porosan silih asih sebagai lambang dewa Tri Murti, kapur simbol Dewa Iswara, base simbol Dewa Wisnu, dan gambir simbol Dewa Brahma. Kwangen juga simbol om kara yaitu aksara suci sebagai simbol Ida Sang Hyang Widhi Wasa. Daksina pengadeg atau pralingga sebagaimana disebutkan dalam lontar Krama pura adalah sebagai lambang lingga Stana para ista dewata.

Sebuah pengadeg atau pralingga tidak pernah lepas dari menggunakan canang didalamnya. Tujuan menggunakan canang dalam pemujaan Hindu adalah untuk mendapatkan tuntunan dari Tuhan dalam segala manifestasinya sebagai Sanghyang Tri Murti.

Dalam canang itu terdapat juga simbol-simbol yang menggambarkan sikap yang semestinya diwujudkan untuk mencapai karunia Sanghyang Tri Murti simbol tersebut misalnya setiap canang sampiannya dibentuk dengan ringitan dan tatuasan. Dalam lontar yajnya Prakerti disebutkan bahwa reringitan dan tetuwasan itu lambang kelanggengan karyajnya. Bunga lambang kesucian dan ketulusan hati. Sejatinya karunia Tuhan Dewa Tri Murti dapat dicapai melalui ketulusan dan kesucian hati yang langgeng. Demikian dalamnya makna sebuah pengadeg atau pralingga, maka dari itu dalam lontar Krama pura tidak boleh sembarangan orang menurunkan dan melukar dari dalam pelinggih atau tempat suci.

\subsection{Nilai-nilai Pendidikan Susila}

Kata susila berasal dari bahasa sansekerta dari hati kita su yang mengandung arti baik dan kata sila artinya tingkah laku, watak, kelakukan baik, moralitas. (Putra Pudharta, 2005 : 114). Susila mengandung arti tingkah laku yang baik. Yang tergolong tingkah laku yang baik adalah tingkah laku yang sesuai dengan norma-norma yang berlaku, baik norma agama, norma hukum, norma kesopanan, norma adat istiadat. Demikian pula sebaliknya tingkah laku yang disebut buruk adalah tingkah laku yang bertentangan dengan norma - norma yang berlaku, baik norma agama, norma hukum, norma kesopanan dan norma adat. Dalam kitab Wraspati tattwa dinyatakan sila ngaranya angraksa acara rrkayu, artinya sila adalah melaksanakan perbuatan yang baik (sudirga, 2009...)

Dalam lontar Krama pura menjelaskan tentang tata susila secara lebih mengkhusus tentang tata acara aturan-aturan memasuki areal pura agar pura tetap terjaga kesuciannya. Untuk mengetahui nilai-nilai pendidikan susila yang terkandung dalam lontar Krama pura, berikut ini kutipan beberapa isi lontar Krama pura. Bagi umat yang sedang dalam keadaan cuntaka dilarang masuk areal pura sampai batas waktu cuntakanya berakhir. Menurut lontar Krama pura batasan cuntaka diatas sebagai berikut.

Malih yan wenten jadma kari cuntaka bevating pejah, angen-angen cuntakanya. Yening di banjar tigang dina cuntakanya. Yanya sanak anisan, ro ming telu saking lanang 37 dina cuntakanya, yan wong janga jati yenya wesya 27 dina cuntakanya, yan satriya 24 dina cuntakanya, yan sang Brahmana 7 dina cuntakanya, yen pemangku kahalangan mati ngarep ring umahnya 3 dina cuntakanya, yen sang 
Brahmana pandita tan hana cuntakanya (lontar kramapura, 4).

Terjemahannya

Lagi bila ada orang yang masih cuntaka karena kematian, batas-batas cuntakanya. Kalau dibanjar tiga hari cuntakanya kalau keluarga misan, mindon, mingtelu dari yang laki-laki 37 hari cuntakanya bila orang janga jati, bila golongan Wesya, 27 hari cuntakanya, bila golongan satya 24 hari cuntakanya, bila sang Brahmana 7 hari cuntakanya. Bila pemangku, ada keluarga dekat meninggal dirumahnya, 3 hari cuntakanya. Bila seorang sulinggih tiada cuntaka (Tim Penterjemah, 2008 : 4).

Tentang batas waktu cuntaka akibat kematian tidak ada keseragaman di masing-masing desa pakraman di Bali, biasanya batas cuntaka itu diatur dalam awig-awig desa pakraman, sehingga satu desa perlu ada kepastian. Hal tersebut dapat dibenarkan oleh agama Hindu, karena agama Hindu menerima desa kala patra dan catur dresta yang berlaku di masing-masing desa pakraman. Dengan demikian batas waktu cuntaka karena kematian tidak dapat menerapkan aturan yang baku seperti ucapan sastra, tetapi bersifat situasional, tergantung kesepakatan atau pararem krama desa pakraman. Disinilah teruji pleksibilitas dari agama Hindu.

Larangan bagi umat Hindu yang sedang dalam keadaan cuntaka memasuki areal pura adalah suatu pendidikan etika bagi umat Hindu agar menghargai dan menghargai tempat suci agar selalu terjaga kesuciannya. Orang yang dalam keadaan cuntaka dianggap dalam keadaan kotor secara phisik dan dalam keadaan leteh secara spiritual, sehingga ia diberikan dispensasi untuk kegiatan kesucian yang berkaitan dengan tempat suci atau pura lontar krama pura yang juga mengatur batas cuntaka bagi pemangku, apabila nabenya meninggal dunia, adapun aturannya sebagaimana ucapan lontar krama pura sebagai berikut.

Yen wenten prenah siwanya lina, I pemangku wenang cuntaka, 12 dina, kango sisya liyanan wenang cuntaka, 12 dina, kangp sisya liyanan wenang 14 dina cuntakanya. Sepatutnya taler maprascita, yening durung puput pamargine sekadi ucaping arep. Pradene raris mangaturang canang ke pura, ika wenang sama-sama danda ,gur artha 1700, rawuh ing ngaturang penyepuhan pura ika ngaran,

\section{(Lontar kramapura,4)}

\section{Terjemahannya}

Bila ada dari siwanya (Pendita) yang meninggal, seorang pemangku patut cuntaka 12 hari, sisi yang lain 14 hari, setelah berakhir lalu mensucikan diri dengan prayascita, bila belum selesai seperti jalannya didepan, apabila telah menghaturkan canang ke pura, hal itu patut kena denda sebesar 1700 dilengkapi dengan menghaturkan penyucian pura

(Tim Penterjemah, 2004 : 4).

Aturan cuntaka bagi pemangku apabila nabenya meninggal dunia adalah suatu pendidikan moralitas bagi pemangku untuk menghormati sang nabe sebagai gurunya yang selalu memberikan bimbingan sampai tahap melaksanakan pewintenan kepemangkuan. Hal tersebut sangatlah logis, karena seorang sisya semestinya memberi penghormatan yang tinggi 
terhadap gurunya, bahkan dalam kitab siwa sambita mengajarkan bahwa seorang guru harus dihormati seperti ayah dan ibu bahkan diperlakukan seperti Tuhan, apa bila ia seorang guru spiritual yang bijaksana. Selengkapnya kitab Siwa Samhita menyatakan sebagai berikut.

Guruh pita gurur mata gurur devo na samsayah

Kar mana manasa vaca tasmat sarvaih prasevyate

(Siva Samhita III.13)

Terjemahan

Tak ada keragu - raguan sedikitpun bahwa guru adalah ibu, guru adalah ayah bahkan guru adalah Tuhan dan demikian ia harus dihormati ia harus dilayani oleh semuanya dengan pemikiran, ucapan dan perbuatannya

(moswinara, $2000: 44$ )

Menurut pendapat IB Sunantara (informan). Penghormatan kepada guru seperti sabda kitab Siwa Samhita tidaklah berlebihan, sebab seorang guru pada hakikatnya adalah seorang guru pengajian yang dapat menghapus kegelapan siswa, ia adalah penjaga dan penegak moral dan spiritual, ia juga penjaga peradaban penjaga kebudayaan dan sebagai penegak jati diri bangsa. Pantaslah seorang guru mendapat penghargaan dan penghormatan yang tinggi.

Orang yang amoral seperti pencuri kemudian mencuri ke pura, yang dicurinya adalah benda - benda yang disucikan, mendapat hukuman yang amat berat, karena ia telah mencemari kesucian pura. Sebagaimana pandangan lontar krama pura berikut ini.

Malih yen wenten amandung padruwean Widhi, sane magenah ring pakarangan pura ika, agung alit etang pangarganya kang kapaling, yen nista danda gung arta 500, yen madya danda 1500, yen uttama, danda dosane. Wraspati, gung artha 5700. apan pura ika kaletukan dening tampaking pandung, teka wenang I pamale san mangaturang guru piduka, manyawang mwang caru manca kelud, apan dahat cemernya, sama kalanya lawan jadma pejah ring pura, karananing wenang Ipamaksan mangaturang prayascita luwih. Wong corah ika wenang ngentosin palinggih durane sami ring pura ika, turing kayogya ngaturang karya pamuput. Sakramaning karya ngadegang pura mamungkah, pepek tekaning padaginganya, palinggih purane ika, tka wnang kasagara, sama danda mwang parikramanya tunggal lawan masanggama ring pura, amantenin wong ring pura maneher sahika dandanya ngaran (Lontar Kramapura : 5)

Terjemahannya

Dan lagi bila ada yang mencuri benda suci, yang ada di areal pura itu, besar kecil perhitungan denda terhadap yang dicuri, bila nista (kecil) sebesar 500 , bila menengah 1500 , sedangkan utama (besar) hukuman sangat berat dosanya sebesar 5700. karena pura itu dicemarkan oleh jejak kaki pencuri, hal itu hendaknya I pamaksan mempersembahkan guru piduka ke semua arah dan caru manca kelud, sebab amat tercemarnya, sama kotornya 
dengan orang yang meninggal di pura, sebabnya patut Ipamaksan mempersembahkan pryascita utama. Pencuri itu hendaknya mengganti semua palinggih yang ada di pura itu. Selanjutnya harus melaksanakan upacara selengkapnya. Seperti halnya upacara membuat pura baru, lengkap dengan pedagingannya palinggih pura itu hendaknya dilanjutkan ke laut, sama dendanya dengan orang yang bersetubuh, di pura amat berdosa orang itu, selanjutnya itulah dendanya (Tim Penterjemah, $2008: 6$ ).

Mencuri adalah mengambil barang orang lain tanpa ijin pemiliknya. Tindakan mencuri itu tergolongkan dalam asta dusta menurut kitab slokantara mencuri itu bertentangan dengan norma-norma yang berlaku, baik norma agama, norma hukum, norma kesopanan maupun norma adat, karena itu dilarang oleh agama manapun. Dalam kitab Sarasamuscaya dikatakan bahwa perbuatan mencuri dapat merusak tatanan catur Purusaartha sebagai landasan hidup umat Hindu, maka dari itu perbuatan mencuri harus dihindari, selengkapnya kitab Sarasamuscaya menyatakan sebagai berikut.

Ya dhananya pakar santi narah

Swa bacama sritah

Na hared dharma kamanca

Pramusanti nasam satah

Yapwan kraman ikang wwang angalep masning mamas maka panghada kasaktinya, kweh ning hambanya tatan mas nika juga malap nika, apa pwa dharma artha, kama nika mila kalap denika (Sarasamuscaya : 149)
Terjemahannya

Jika ada orang yang merampas kekayaan orang lain dengan berpegang kekuatannya dan banyak pengikutnya, malahan bukan hanya kekayaan hasil curiannya saja yang dirampas darinya, tetapi juga dharma, artha dan kamanya itu turut terampas oleh karena perbuatannya (kajeng 1994 : 79).

Pandangan kita Sarasamuscaya tentang akibat pencuriannya dapat mengakibatkan hilangnya barang orang lain (Artha), hilangnya kesukaan orang lain (kama), runtuhnya kebajikan (dharma). Karen aitu hindarilah tindakan pencurian. Lebih lanjut kitab sarasamuscaya melukiskan bahwa seseorang yang tidak pernah mencuri ia akan selalu ceria dan bahagia, dan selalu merasa bebas dan lapang kemanapun ia pergi, namun sebaliknya, bagi orang yang suka mencuri akan sangat terbatas geraknya, karena gerak geriknya sangat mencurigakan dan selalu curiga terhadap orang lain, sebagai mana ditanyakan dalam kitab Sarasamuscaya berikut ini.

narah

Aharan kasyarid Dravyam yo

Sukhamavaset, sarvatah

Sankitah steno mrgo grama mi vagatah.

Kunang ikang wwang tapwan kana pwa inalapnya, drebyaning asing - asing, ya ika wastuning tan kana katakutnya. Litasing saparanya, kunang ikang maling ngaranya, sakwanyan sarwa sangsaya iriya nihan padanya kali kramaning mara ring grama. (Sarasamuscaya : 150). 
Terjemahan

Orang yang sekali-kali tidak ada yang dicurinya (tak pernah mencuri, barang-barang kepunyaan siapapun juga, baginya sesungguhnya tidak ada yang ditakutinya, selalu gembira kemanapun perginya, sebaliknya yang disebut pencuri, kemampuan perginya serba merupakan kecurigaan baginya, demikianlah sama halnya seperti seekor kijang atau seekor binatang liar yang masuk ke dalam desa (Kajeng, 1994 : 79)

Pencurian yang dilakukan di luar tempat suci saja sangat dilarang oleh sastra agama. Orang yang mencuri di tempat suci bila ketahuan akan kena tiga jenis denda ( tridana) yaitu : artha denda, denda dengan arta benda, ini sesuai dengan besar kecilnya kerugian, sangaskara danda, denda dengan melaksanakan upacara penyucian di pura dan jiwa danda, denda pidana kurungan badan, dan dikucilkan oleh krama desa pakraman. Denda bagi pencuri di pura menurut lontar Kramapura menerima hukuman sangat berat, sampai mengganti pelinggih dan melaksanakan upacara pemlaspasan, menurut lontar karma pura bukan harga barang yang dicuri menjadi ukuran dalam menganjar para pencuri barang-barang pura. Tetapi langkah pencari yang masuk pura telah mencemari kesucian tersebut, meskipun harga barang yang dicuri harga nominalnya sangat kecil, oleh karena itu bagi umat Hindu diinbau janganlah coba-coba mencuri di pura, hal tersebut melecehkan agama sendiri. Ganjaran yang sangat berat bagi para pencuri pura merupakan pendidikan modal bagi umat agar jangan sampai melakukan perbuatan yang mencemarkan kesucian pura, justru kesucian pura wajib dijaga oleh umat Hindu sendiri.
Menurut lontar Krama pura, bukan hanya perbuatan tercela seperti mencuri yang mendapat hukuman berat, tetapi orang yang berkata kotor kotorpun harus diberi hukuman, karena perkataan kotor juga dapat mencemarkan kesucian pura, seperti ucapan lontar krama pura berikut ini.

Malih yan wong mangopak di pura, mwang amisuh, masabda cremcem, Irusuh, mwah jarak di pura, yan kalaning patetoyan, pura rahinan, twitan patetoyan, pararakinon, makadi risedek ma ngaturang banten, yan sampun sajroning penyengker pura, mako kage I Klian pura menglemekin makadi mituturin jadma ika, yanya murug, age iklama pamaksan mangejuk jadma, ika, saha nulakang keumahnya, yanya majwalan wenang dosa jadma ika soang-soang, kawenang mangaturang prayascita lewih ring palinggihe, nwang nyepuhin I Pemangku, apan dosa kasinakang anundung dewa, ngundang bhuta kala dengen, pada teka manyarangin maring pura ika magawi kali satata (lontar Krama pura: 6).

Terjemahan

Lagi bila ada orang yang marah menegur di pura, dan memaki-maki berbicara kotor di pura, bila saat upacara piodalan juga saat tidak ada piodalan, atau saat menghaturkan sesajen, apabila ada di wilayah pura, hendaknya Iklian pura menasehati orang tersebut, bila dilanggar, hendaknya I Krama pemaksan menangkap orang itu, dan mengembalikan kerumahnya. Bila membangkang, hendaknya orang itu dihukum masing-masing, serta menghaturkan prayascita utama di pelinggih serta menyucikan I pemangku, karena bersalah telah mengusir Dewa dan mengundang 
bhuta kala dengen, semua datang menghancurkan pura itu, senantiasa membuat cemar.

(Tim Peterjemah, $2008: 6$ )

Marah dalam dasa mala kuhaka, suka mencari kesalahan orang lain, kemarahan merupakan awalnya kehancuran, awalnya seseorang melakukan kejahatan. Pandangan yang sama dinyatakan dalam kitab Bhagawadgita sebagai berikut.

krodhad Bhawati sammohah

Samohat smriti wibhramaa

Srtibhramsad budhdhi naso

Buddhisat prahasyati

(Bhagawadgita II.63)

Terjemahannya.

Dari amarah timbul kebingunan, dari kebingungan hilang ingatan, dari hilang ingatan menghancurkan pikiran, dari kehancuran pikiran menimbulkan kemusnahan (Pudja 1984 : 63).

Percekcokan, kealpaan, kejahatan kekacaon bermula datang dari kemarahan, bahkan dalam kitab Bhagawadgita menegaskan bahwa pintu neraka datang tiga sebab yaitu :

Tri widham Narakasye'dam

Dwaram nasanam atmanah

Kamah Krodhas lobhas

Tasmad etat trayam tyejeg

(Bhagawadgita XVI-20)

Terjemahannya

Ini pintu gerbang ke neraka, jan menuju jurang kehancuran diri ada tiga penyebab yaitu, kama, krodha dan lobha, oleh karena itu ketiga-tiganya harus ditinggalkan (Pudja, 1984 : 356).

Tiga pintu gerbang yang dapat menjerumuskan ke neraka yaitu kama artinya kenafsuan, orang penuh nafsu cendrung berbuat sesuai dengan dorongan nafsunya seperti tidak bisa diatur, selalu ingin memuaskan indriyanya tidak tahu malu dan sebagainya. Krodha artinya pemarah, marah yang tidak terkendali atau tidak bisa direndam oleh kekuatan rohani dapat pula mengantar seseorang ke pintu neraka. Orang yang suka menyimpan marah ibarat menyimpan sampah busuk dalam jiwa. Hal itu pada saatnya akan menjadi penyakit pikiran dan tubuh wadah sang atman. Pintu gerbang neraka yang ketiga adalah lobha atau tamak. Sifat lobha disebabkan oleh dominannya guna tamas terhadap guna sattwam dan rajas menjadi unsur pendorong guna tamas. Dalam ilmu pengetahuan ada nafsu yang disebut nafsu distinksi (Wiana, 1997 : 23). Kalau nafsu distinksi ini yang menonjol, orang akan selalu ingin lebih dari pada orang lain, ingin lebihnya menjadi berlebih-lebihan tanpa mau melakukan pengorbanan, nafsu lobha inilah yang akan menjerumuskan seseorang ke alam neraka.

Larangan untuk marah, berkata kotor dan berkata cabul di areal pura, dan dikembangkannya denda bagi orang yang berkata kotor diareal pura, merupakan pendidikan susila bagi umat Hindu agar umat Hindu mempunyai moral yang baik, budi pekerti yang kukuh, dan hal itu dimulai dari pura dan perlu ditularkan pada setiap tempat dan setiap waktu, sehingga orang beragam bukan hanya di pura, tetapi dimana saja patut melaksanakan kaedah - kaedah agama.

\subsection{Nilai Pendidikan Upacara}

Kata upacara berasal dari bahasa sansekerta, dari kita upa yang artinya dekat, dan cara artinya 
kedalaman, sikap, pelaksanaan, pelayanan, penghormatan

Samadiastra, 1984 : 64). Upacara adalah rangkaian tindakan dalam kegiatan ritual. Kata upacara dalam konlontar agama Hindu adalah tindakan nyata dalam pelaksanaan tattwa agama Hindu yang didukung dengan upacara atau sesaji, yang di Bali disebut banten.

Nilai-nilai pendidikan upacara yang terkandung lontar Krama pura lebih bersifat mengkhusus pada upacara pemarisudha kahyangan karena terganggunya kesucian Kahyangan. Terganggunya kesucian Kahyangan tersebut diakibatkan oleh ulah manusia yang berkata - kata kotor jorok, cabul, dan ulah tindakan manusia yang mencemari kesucian pura menurut pandangan agama Hindu. Misalnya tindakan mencuci, bertengkar berkelahi sampai keluar darah, berpacaran, berstubuh, naik diatas pelinggih tanpa ijin, orang masih cuntaka masuk pura, orang gila barulah dipura. Terhadap tindakan - tindakan seperti tersebut di atas, patut dilakukan upacara pamarisudha Kahyangan, karena tindakan seperti tersebut dapat mengganggu kesucian pura menurut sastra agama Hindu. Oleh karena wajib dilakukan upacara pemarisudha kahyangan (pura)

Berikut ini dijelaskan beberapa upacara pemarisudha pura menurut lontar Krama pura, yang diakibatkan oleh ulah atau tindakan manusia yang salah di wilayah pura. Selengkapnya sebagai berikut. Apabila diareal pura ada orang yang bertengkar, sampai berkelahi dan sampai mengeluarkan tetesan darah wajib diadakan uapacara pemarisudha pura. Selengkapnya, berikut, berikut ucapan lontar krama pura.
Mwah yan hana mayuda ring pura, turing maciri ya katon sumirat rahnya ring nata ring pura ika, teka wnang danda jadma sahika pada soang-soang 10500, madulurang ngaturang panyepuhan, mapadudusan caru manca kelud ngaran ( lontar krama pura, 6)

Terjemahannya

Dan bila ada orang berperang di pura, serta telah terbukti adanya percikan darah di pelataran pura itu, hendaknya orang tersebut dihukum masing - masing 10500, dilengkapi dengan penyucian, upacara padudusan dan caru manca kelud.

Menurut lontar krama pura, pertengkaran, sampai perkelahian yang terjadi di pura sampai mengeluarkan tetesan darah, mendapat hukuman berupa sangaskara danda cukup keras yaitu menghaturkan upacara pedudusan dan dengan caru panca kelud . caru panca kelud dasarnya lima ekor ayam dan kambing hitam. Hal tersebut cukup logis, karena tetesan darah karena perkelahian dapat menimbulkan keletehan di pura, sehingga kesucian pura akan luntur, dan akan berpengaruh pada umat penyungsungnya. Oleh karena itu umat harus menghindari perkelahian di areal pura. Pura disamping digunakan untuk memohon kerahayuan, sering pula dimanfaatkan oleh umat untuk mohon dewa sraya, yaitu mohon taksu dan mohon kesidian sesuai dengan tujuan orang yang melakukan dewa sraya. Apabila ada orang yang melakukan upacara dewa sraya secara diam-diam tidak menyertakan pemangku pura, maka orang bersangkutan patut mendapatkan hukuman, sebagai mana pandangan lontar krama pura berikut ini 
Malih yan wenten jadma matingkah kadi minat ica makadi madewa sraya, tan wenten sareng I pamangku lajnya mungguh ke gedong, tur suwe ipun magenah irika ring tengah, nging yan wong liyan ring pamaksan, tka wnang dosa jadma ika wratpasti, danda gung artha, 57.000, apan wenang dalahen wong ika makena panyalah ngaran (lontar krama pura: 8)

\section{Terjemahan}

Lagi bila ada orang yang bermaksud mohon anugrah seperti dewa sraya, tidak menyertakanpemangku terus raja ia naik kegedong, bila orang itu bukan anggota pemaksan. Hendaknya orang itu dihukum keras, dendanya sebesar 57000, karena orang itu telah memasang perangkap (Tim penterjemah $2008: 8$ ).

Lontar krama pura berikutnya menyatakan tentang denda berupa sangsara danda sebagai berikut.

Yening sama wong pemaksan atingkah samangkana kayogyane dosa, gung artha 4200 saha ngaturang panganten padudusan, ring pada bhatara ring pura ika, maduluran pamrascita, sahur Ida Sang Wiku putus wnang adhiksanin, apang dosane wong ika langgah langgana (lontar Krama Pura: 8).

Terjemahannya

Bila yang melakukan itu adalah anggota pemaksan di denda sebesar4 200, serta melakukan upacara padudusan kepada Bhatara yang ada di pura itu dilengkapi dengan prayascita, yang dipuput oleh Ida Sang Wiku putus yang telah menjalankan diksa sebab salah orang itu telah berani lancang (Tim Penterjemah, $2008: 8$ )
Apabila dibandingkan denda orang yang melakukan dewa sraya di pura dengan tidak menyertakan pemangku (nyilib bahasa bali) antara orang yang tidak ikut menyungsung pura itu. Denda material lebih besar ditimpakan terhadap orang tidak ikut sebagai penyungsung pura itu dibandingkan orang yang ikut sebagai penyungsung. Tetapi denda berupa sangkara danda dengan menghaturkan upacara prayascita dan padudusan ditimpakan kepada orang yang ikut menyungsung pura itu. Hal ini dipahami, karena seorang penyungsung semestinya ikut menjaga kesucian pura justru mencemari puranya sendiri. Hal ini merupakan suatu pendidikan bagi umat pengemong agar senantiasa selalu menjaga kesucian, tempat suci yang menjadi tanggung jawabnya. Sebuah pura yang dicemarkan oleh pengemponnya sendiri., sama pepatah pagar makan tanaman, supayahal ini tidak terjadi, maka perataran dan tata tertib di pura mesti diketatkan, dan perangkat hukum harus dikuatkan. Karena alasan itulah lontar krama pura menjatuhkan denda yang berat pada pengempon pula yang mencemarkan tempat sucinya sendiri.

Upacara agama di Bali biasanya selalu disertai dan ditunjang oleh yang namanya Panca gita, yaitu lima jenis suara, yang terdiri dari (1) suara puja, (2) suara genta, (3) suara kidung warga sari (4) suara gambelan, gong angklung dan suara kulkul (Dharma Sandhi), apa bila pada saat upacara keagamaan sedang berlangsung, para bhakta sedang melantumkan hidung wargasari tiba-tiba ada masyarakat yang berkata tidak sopan menyumpat (memisuh). Orang tersebut dikenakan denda sesuai dengan sabda lontar krama pura berikut ini. 
Malih dikalaning I pemangku ngaturang canang, makadi piodalan bhatara ring pura pangiwian lawatnya madulurang kidung wargasari, kala sampunika raris wenten jadma anak, mapajar creceni, saha mamisuh, jadmane sahika wnang danda ngaturing banten panyepuhan, mwah kayogya mangenteg linggih, saparikramanya, apan ya dosa nyampuri angucap anyampahi ring pura (lontar kramapura: 8).

Terjemahannya

Dan lagi pada saat pamangku menghaturkan canang, utamanya pada saat piodalan Ida Bhatara di pura yang disungsung, upacaranya dilengkapi dengan kidung wargasari, saat itu ada orang yang berkata sembarangan, serta memaki-maki orang itu hendaknya menghaturkan, serta menghaturkan upacara ngenteg linggih, sebagaimana mestinya karena bersalah berucap, meremehkan pura itu namanya (Tim Penterjemah, $2008: 8$ ).

Saat upacara keagamaan sedang berlangsung adalah saat dimana para bhakta dapat menyucikan pikiran perasaan dan budhinya agar mendapat asung kerta wara nugraha dari Tuhan. Tabu bagi para bhakta untuk berkata kotor saat upacara keagamaan sedang berlangsung. Bila saat itu ada orang yang berkata sembarangan dan mengeluarkan hujatan (memisuh). Maka wajarlah ia di denda dengan melaksanakan upacara penyucian pura kembali. Lagi hanya orang yang berbuat demikian mencemarkan kesucian areal pura dan mencemarkan kesucian yadnya. Sehingga ia telah melakukan dua kesalahan sekaligus dalam satu tempat.
Ucapan atau kata - kata adalah alat yang paling ampuh untuk kemunikasi, untuk menyampaikan informasi dan untuk menerima informasi. Ucapan digunakan untuk mencari teman dan mencari rezeki, bila orang benar cara berkata, maka temanlah didapat, bila salah berkata, maka musuhlah yang didapat, bahkan dapat mendatangkan kematian. Sebagaimana pandangan kitab Niti sastra berikut ini.

Wasita nimitanta manemu lakshi
Wasita Nimittanta pati
kapanggah
Wasita nihittanta manemu
duhka
Wasita nimittanta manemu mitra
(Kakawin Niti sastra V.3)

Terjemahannya

Oleh perkataan engkau mendapat bahagia

Oleh perkataan engkau menerima ajal Oleh perkataan engkau mendapatkan kesusahan

Oleh perkataan engkau mendapatkan sahabat

Kutipan kekawin niti sastra di atas memberi pesan betapa pentingnya menjaga dan mengembalikan ucapan agar tidak menderita akibat ucapan yang kita ucapkan sendiri. Uraian berikutnya lontar krama pura menjelaskan tentang larangan orang yang masih cemer masuk wilayah pelataran pura. Yang termasuk orang cemer menurut contoh krama pura adalah sebagai berikut.

Malih yen wenten jadma cemer padgata kala ring pura, lwire ne mawasta cemer jadmane sampun manas eneng kalih mengenteh meju, mlalung, menahang kamben ring pura, sajroning panyengker pura, jadma sahika wnang 
danda mangaturang pakeludan ring pura ika, antuk caru panca sata ngaran (lontar kramapura : 8)

Terjemahan

Lagi bila ada kebetulan kotor saat ada di pura misalnya, yang disebut orang yang kotor saat itu seperti orang yang baru kotor kain, kencing, berak. Telanjang, memperbaiki kain di pura, dilingkungan pura, orang itu patut mempersembahkan pakeladan di pura, dengan uapacara caru panca sata.

(Tim Penterjemah : $2008: 9$ )

Sungguh sangat tidak sopan apabila secara sengaja orang telanjang, kencing dan berak disekitar pura. Karena itu pura saat ini harus dikelola secara moderen, untuk tetap menjaga kebersihan dan kesucian pura, alangkah baiknya disetiap pura disiapkan kamar mandi WC dan tempat berganti pakaian. Sehingga apabila diantara pemedek yang kebelet, agar segera ada tempat yang layak dan tertutup untuk mengatasi kebelet tersebut. Di samping itu para pemedek yang akan ke pura harus memastikan diri dalam keadaan sehat, tidak dalam keadaan sedang menderita diare, sehingga tidak menganggu kondisi di pura. Diantara ribuan umat yang tangkil di pura, pasti ada saja diantara pemedek yang berkeinginan membuang air besar dan kencing serta pakaiannya lepas, hal inilah yang menyebabkan disetiap pura pelen dilengkapi dengan fasilitas WC, kamar mandi dan tempat berganti pakaian.

Pada umumnya disetiap pura di Bali pasti mempunyai pemangku, dimana dipemangku berkewajiban melayani umat dalam kaitan dengan yadnya. Seseorang yang berstatus sebagai pemangku, wajib melalui proses upacara penyucian diri yang disebut upacara pewintenanan agar dapat melaksanakan tugas kepemangkuan nya menurut lontar krama pura pewintenan menjadi pemangku tidak harus upacara besar. Tetapi upacara besar. Tetapi upacara sederhana pun dapat dilakukan, sebagaimana pandangan lontar krama pura berikut ini.

Nihan tingkahe ngadegang pamangku, yanya tan kari santananya saking lanang, wnang I pemaksan sami mamilih, pacang pamangku, nanging upakaraning dumun sapari polaheng pamangkane pinih alit pangambile, mapadengenan ring dewa, ka jaya-jaya aksara de sang pandita yogi (lontar kramapura : 9)

Terjemahannya

Inilah caranya memilih pamangku, bila ia telah tiada keturunannya yang laki-laki menggantikan, hendaknya pemaksaan semua memilih pemangku namundi upacara dulu, sesuai dengan upacara menjadi pemangku paling kecil diambil, mohon izin kepada dewa serta pawintenan triguna serta marajah, di upacarai oleh sang sulinggih siwa yogi.

(Tim Penterjemah : $2008: 10$ )

\section{Lontar Krama pura} memberikan pendidikan kepada umat, dalam hal melakukan upacara yang besar, tetapi pilih lah upacara yang sesuai kemampuan umat, agar yadnya itu dapat dilakukan dengan iklas tanpa merasa terpaksa dan terbebani dengan berat. Demikianpula halnya dengan pewintenan pemangku, upacara terkecil pun bisa dilakukan, namun hal yang pokok tidak boleh dihilangkan, yaitu merajah dalam diri pamangku, karena hal ini merupakan hal yang sangat 
prinsip dalam uapacara pawintenan. Setelah seseorang diupacarai pawintenan dan berstatus sebagai pemangku kemudian pamangku istri meninggal, sehingga pamangku berstatus denda (tan bulangkep), apakah pemangku yang dalem keadaan duda boleh kawin lagi? Berikut ini pandangan lontar Krama pura tentang hal tersebut.

Risampun umadeg pamangku, malih ya memanah angamet stri, riwusnya apawarangan, wnang sira pamangku nyepuh dewekne, mwang mangaturang panyepuhan ring palinggih ring pura, Strinya ika juga wnang inuparanin mwang nyepuh mwah mawinten pabresihan kadi kungkungnya, apan saselwaning laku ngaran (lontar kramapura : 10).

Terjemahannya

Setelah berstatus sebagai pemangku, lagi ia bermaksud, setelah perkawinan itu, hendaknya pamangku itu menyucikan dirinya, serta menghaturkan penyucian pada pelinggih di pura, istri barunya juga diupacarai dan menyucikan diri mawinten suci seperti suaminya. Karana salah jalan namanya (Tim Penterjemah, $2008: 10$ ).

Lontar krama pura sangat toleransi dan sangat manusiawi terhadap status seorang pemangku, bila ia berniat kawin lagi asalkan melalui proses penyucian kembali setelah uapacara perkawinan berlangsung, pentingnya seorang pamangku dalam berstatus lengkap (suami istri) pada hakikatnya semata-mata bukan hanya bertujuan untuk tujuan biologis saja, tetapi lebih dari itu, karena kewajiban seorang pemangku istri cukup berat dan cukup banyak terutama dalam bidang wangun upakara. Pamangku lanang tanpa pamangku istri tentu tidak dapat menyelesaikan tugas-tugas membuat upakara untuk kepentingan yadnya. Dalam agama Hindu secara umum memberikan penghormatan yang tinggi terhadap setatus sebagai wanita, karena seorang wanita adalah pelanjut keturunan yang tidak dapat digantikan oleh siapapun. Dalam kitab yajur weda dinyatakan, Tuhan akan menganugrahi umur yang lebih panjang kepada kaum wanita, karena wanita dapat melindungi keberlangsungan kehidupan dunia, dapat melindungi keberlangsungan kehidupan dunia sebagai sabda yujur weda berikut ini.

$$
\begin{aligned}
& M \bar{u}{ }_{r d h} \bar{a}_{\text {asi } R} \bar{a}_{d} \text { Dhrawa asi } \\
& \text { dharun }^{\bar{a}} \\
& \text { Dh } \overline{\bar{a}} \text { rtyasi Dharani } \\
& \text { Ayuse tw } \overline{\bar{a}} \text { varcase tv } \overline{\bar{a}} \text { krsyai } \\
& \text { tva ksem } \bar{a} \text { ya tva } \\
& \text { (Yajur veda } 14: 21 \text { ) }
\end{aligned}
$$

Terjemahannya

Wahai para wanita, yang berumah tangga, engkaulah yang tertua di rumah ini, engkaulah yang cerdas dan seimbang di rumah ini dan engkau sebagai pendorong dan sebagai perawat yang memberikan ketenangan. Engkau yang menetapkan peraturan seperti ibu pertiwi yang melindungi dunia, oleh karena itu, aku memberikan mu umur panjang dan cahaya keberhasilan dan pertanian (usaha) dan untuk kemakmuran di dunia ini (Somvir, 2001 :165)

Seperti terdapat dalam banyak mantra vedan, posisi wanita begitu tinggi. Tanpa kehadiran wanita, sebuah rumah tidak dapat dikatakan utuh, karena tidak akan ada pelanjut keturunan. Kitab banawa dharma sastra 
menyatakan wanita sebagai pelanjut keturunan dilibatkan seperti tanah atau bumi dimana bumi dapat memberikan makanan pada setiap mahluk dan tempat bertumpu semua mahluk. Selengkapnya kitab manawa dharma sastra menyatakan sebagai berikut.

\section{Ksetrabh $\bar{u}$ ta smrta nare \\ Bija bautah smrtah pam $\bar{a}_{h}$ \\ Ksetrabija s $\bar{a}_{\text {mayog }} \bar{a}_{t}$ \\ ${ }_{s} \bar{a}$ mbawah sarwa dehwan}

(Manawa dharma sastra IX : 33)

Terjemahannya

Menurut smerti, wanita dinyatakan sebagai tanah, laki-laki dinyatakan sebagai benih, hasil terjadinya jazad badaniah yang hidup terjadi karena melalui hubungan antara tanah dengan benih (Subali, 2008 : 17).

Demikian pentingnya kodrat sebagai wanita penerus keturunan karena itu lontar Krama pura pun menyatakan pentingnya kehadiran seorang pemangku wanita dalam keluarga pemangku guna melaksanakan swadharma sebagai pelayan umat.

\section{PENUTUP}

Nilai-nilai pendidikan agama Hindu yang terkandung dalam lontar Krama pura antara lain : (a) Nilai pendidikan tattwa, yang menyatakan Tuhan maha gaib yang tak dapat dijangkau oleh pikiran dan indria dan tak dapat mempengaruhi oleh dunia, karena itu untuk mempermudah umat mendekatkan diri kepada Tuhan, Beliau dapat dipuja ditempat suci dengan menggunakan media berupa pralingga pratiwi, arca atau pengadeg. Tidak sembarangangan orang boleh menghias pengadeg dan tidak boleh sembarangan orang menurunkan pengadeg dari pelinggih karena pralingga itu merupakan simbol stana Tuhan dan dalam segala manifestasinya, (b). nilainilai pendidikan susila yang lebih menekankan tentang peraturan yang wajib ditaati jika akan masuk ke areal pura, misalkan tidak berkata kotor, jorok, cabul di areal pura, tidak boleh mengkujat, tidak boleh bertengkar, orang yang dalam keadaan cuntaka tidak boleh masuk ke areal pura, tidak boleh berpacaran di pura.

Tidak boleh kencing dan berak di pura, tidak boleh merusak bendabenda milik pura, dilarang mencuri benda-benda milik pura. Bila sesana itu dilanggar akan dikenakan denda sesuai dengan aturan dalam lontar krama pura. (c) nilai-nilai pendidikan upacara yang lebih menekankan pada upacara keagamaan yang wajib dilakukan oleh umat apabila umat melanggar tata tertib masuk pura, berupa upacarabhuta yadnya, yaitu melaksanakan upacara pecaruan besar - kecilnya sesuai kesalahan yang dilakukan oleh umat. Upacara dewa yadnya menghaturkan uapacara prayascita. Padudusan dan pemelaspasan pelinggih bagi umat yang mencemarkan kesucian pura. Upacara Resi Yadnya: yaitu dalam rangka menyucikan seorang calon mangku dengan uapacara pawintenan.

\section{DAFTAR PUSTAKA}

Arifin. 1991. Proses Komunikasi Antara Pendidik Dan Anak Didik. Jakarta: Dirjen Kelembagaan Agama Islam dan Universitas Terbuka. 
Antara. 2008. Sejarah Agama Hindu. Surabaya: Paramitha.

Abdillah, Pius. 2002. Kamus Bahasa Indonesia. Surabaya: Arkola.

Cholid. 1997. Metode Penelitian. Surabaya: Arkola.

Cholid. 1997. Metode Penelitian. Jakarta: Bumiaksara

Denzim. 2001. Teori Dan Pradigma Penelitian Sosial. Yogyakarta: PT. Tiara Wacana.

Fathoni. 2006. Metodelogi Penelitian dan Teknik Penyusunan Sekripsi. Jakarta : Renika Cipta

Hasbullah. 2005. Dasar-Dasar Ilmu Pendidikan. Jakarta: PT. Raja Grafindo.

Idris, Zahara. 1984. Pengantar Pendidikan. Padang: Angkasa Raya

Kadjeng. $\quad$ 1984. Sarasamusccaya. Denpasar: Pemda Bali.

Koentjaraningrat. 1984. Kebudayaan Mentalitet. Jakarta: Gramedia.

Maswinara. 2000. Sivasamhita. Surabaya: Paramitha.

Narbuko, Achmadi. 2008. Metodologi Penelitian. Jakarta: Bumi Aksara. Pudja. 1973

Pudja. 1977. Weda Parikrama. Jakarta: Departemen Agama.
Pudja. 1984. Bhagawadgita. Jakarta: Mayasari.

Pudja. 1984. Sraddha. Jakarta: Mayasari Denpasar.

Pudarta. 2005. Kamus istilah Agama Hindu. Kanwil Departemen Agama Provinsi Bali.

Putra. 2009. Kumpulan Pudja. Denpasar

Semadi Astra. 1984. Kamus Kecil Sansekerta Indonesia. Denpasar: Pemda Bali.

Sudirga. 2005. Widya Dharma VI. Ganesa Exact.

Subali. 2008. Wanita Mulia Istri Dewata. Surabaya: Paramitha.

Teeuw. A. 1984. Sastra Dan Ilmu Sastra, Pengantar Teori Sastra. Jakarta: Pustaka Jaya.

Tim Penterjemah. 2008, Kramapura. Denpasar: Dinas Kebudayaan Provinsi Bali.

Tim Penyusun. 1984. Kekawin Niti Sastra. Singaraja: PGAH.

Tim Penyusun. 2002. Kamus Bahasa Indonesia. Jakarta: Balai Pustaka.

Widia. 1994. Adi Parwa. Denpasar: PT. Upada Sastra.

Zoetmulder. 1994. Kamus Bahasa Jawa Kuna Indonesia. PT Gramedia Pustaka. 